\title{
Adding imagery rescripting during extinction leads to less ABA renewal
}

Citation for published version (APA):

Dibbets, P., Poort, H., \& Arntz, A. (2012). Adding imagery rescripting during extinction leads to less ABA renewal. Journal of Behavior Therapy and Experimental Psychiatry, 43(1), 614-624.

https://doi.org/10.1016/j.jbtep.2011.08.006

Document status and date:

Published: 01/03/2012

DOI:

10.1016/j.jbtep.2011.08.006

Document Version:

Publisher's PDF, also known as Version of record

Document license:

Taverne

Please check the document version of this publication:

- A submitted manuscript is the version of the article upon submission and before peer-review. There can be important differences between the submitted version and the official published version of record.

People interested in the research are advised to contact the author for the final version of the publication, or visit the DOI to the publisher's website.

- The final author version and the galley proof are versions of the publication after peer review.

- The final published version features the final layout of the paper including the volume, issue and page numbers.

Link to publication

\footnotetext{
General rights rights.

- You may freely distribute the URL identifying the publication in the public portal. please follow below link for the End User Agreement:

www.umlib.nl/taverne-license

Take down policy

If you believe that this document breaches copyright please contact us at:

repository@maastrichtuniversity.nl

providing details and we will investigate your claim.
}

Copyright and moral rights for the publications made accessible in the public portal are retained by the authors and/or other copyright owners and it is a condition of accessing publications that users recognise and abide by the legal requirements associated with these

- Users may download and print one copy of any publication from the public portal for the purpose of private study or research.

- You may not further distribute the material or use it for any profit-making activity or commercial gain

If the publication is distributed under the terms of Article $25 \mathrm{fa}$ of the Dutch Copyright Act, indicated by the "Taverne" license above, 


\title{
Adding imagery rescripting during extinction leads to less ABA renewal
}

\author{
Pauline Dibbets*, Hanneke Poort, Arnoud Arntz \\ Clinical Psychological Science, Maastricht University, The Netherlands
}

\section{A R T I C L E I N F O}

\section{Article history:}

Received 28 September 2010

Received in revised form

18 April 2011

Accepted 24 August 2011

\section{Keywords:}

ABA renewal

Human fear conditioning

Extinction

Imagery rescripting

US revaluation

\begin{abstract}
A B S T R A C T
Objective: Although extinction is highly effective in reducing a conditioned fear response, return of the fear response (renewal) outside the extinction context often occurs. The present study investigated whether US devaluation, through imagery rescripting during extinction, resulted in less renewal than mere extinction.

Method: Seventy psychology students were subjected to a fear conditioning paradigm. During fear acquisition CS + was always followed by the US, whereas CS - was never followed by the US. For all groups the acquisition phase took place in context A. During extinction both CS+ and CS- were offered, but no US was presented. For three groups extinction was conducted in a different context, context $B$ (ABA groups). The fourth group received extinction in the acquisition context (AAA group) in order to demonstrate that renewal indeed took place. During extinction, participants received either an imagery rescripting (IR) instruction to devaluate the US (ABAir), a US-unrelated imagination instruction to assess the general influence of imagination (ABAcont), or no instruction at all (ABAno and AAAno). Subsequently, testing occurred for all groups in the acquisition context A.

Results: The results indicated that renewal of the US expectancy ratings was reduced if imagery rescripting (ABAir) was added to mere extinction (ABAno). Next to the reduction in renewal, imagery rescripting (ABAir) also resulted in the devaluation of the US valence, indicating that the mental representation of the US had changed. These findings are not only in line with contemporary conditioning theories, but also suggest that adding imagery rescripting to extinction might be beneficial in the treatment of anxiety problems.
\end{abstract}

(c) 2011 Elsevier Ltd. All rights reserved.

\section{Introduction}

Fear conditioning involves the pairing of a neutral stimulus with an aversive event (unconditioned stimulus, US). This neutral stimulus does initially not evoke an emotional response. However, after repeated pairing with the US the neutral stimulus comes to function as a valid predictor (conditioned stimulus, CS) for the occurrence of the US, resulting in an anticipatory fear response on its presentation (e.g., Watson \& Rayner, 1920).

Conditioning as a theoretical framework has gained enormous power not only to explain the aetiology of fear, but also in therapies that reduce fear. Exposure therapy is a widespread and highly effective method to attenuate a conditioned fear response by means of extinction. In an extinction procedure the CS is repeatedly presented without the US, diminishing the CR. Likewise, in a typical

\footnotetext{
* Corresponding author. Maastricht University, UNS 40, Clinical Psychological Science, P.O. box 616, 6200 MD Maastricht, The Netherlands. Tel.: +31 4338815 97; fax: +31433884155.

E-mail address: Pauline.Dibbets@maastrichtuniversity.nl (P. Dibbets).
}

exposure session patients are also presented with the feared stimulus or situation until the conditioned fear response is extinguished (e.g., Marks, Hodgson, \& Rachman, 1975; Öst, 1989, 1996, 1997). Exposure therapy has proven to be an effective treatment in a variety of anxiety problems such as specific phobias (Öst, 1997), panic disorders (Barlow, Allen, \& Basden, 2007), and post-traumatic stress disorder (Foa, Rothbaum, \& Furr, 2003).

Recent studies have indicated that associative learning can occur even if the CS or the US are not actually present (see for overviews Dadds, Bovbjerg, Redd, \& Cutmore, 1997; Dwyer, 2003; Field, 2006). This implies that the acquisition of a conditioned response can take place if no direct CS-US presentation is experienced. That is, pairing an actual CS with a mentally imagined US can evoke a CR on subsequent CS presentations, and vice versa, a mentally imagined CS can come to evoke a CR after pairings with an actually present US (see for an overview Dadds et al., 1997). Even more, just thinking about a specific CS-US combination, for example imagining that a snake (CS) strangles you (US), might result in a conditioned fear response (but see for an alternative explanation Dadds et al., 1997). 
In a more recent conditioning model presented by Davey (1997) the strength of the CS-US association is not only influenced by the number of experienced pairings of the CS and US. Davey distinguishes two processes, expectancy evaluation and US revaluation, that can affect the CR. The first process stresses the influence of the predictive value or (expected) contingency between the CS and US on the $\mathrm{CR}$. In this process not only direct conditioning experiences determine the associative strength between the CS and US, but also pre-existing beliefs and verbally and culturally transmitted information contribute to the establishment of a CS-US association (see for experiments Askew, Kessock-Philip, \& Field, 2008; Muris, Bodden, Merckelbach, Ollendick, \& King, 2003).

According to the second process, US revaluation, the mental representation of the US can change even if the US is not encountered. For example, socially or verbally transmitted information about the US can inflate or devaluate the US representation resulting in a stronger or diminished CR on subsequent CS presentations (see Davey, 1997; Field, 2006 for reviews).

Next to extinction or exposure procedures, imagery techniques that affect the mental representation of the CS and/or US can be implemented in the treatment of anxiety-related problems (Dadds et al., 1997). According to the model of Davey (1997) a devaluation of the US representation should result in a diminished CR on subsequent CS presentations. Arntz et al. have hypothesized that Imagery Rescripting (IR) might act through US revaluation (Arntz, in press; Arntz, Tiesema, \& Kindt, 2007; Arntz \& Weertman, 1999). This technique has been successfully applied in a variety of anxiety-related disorders such as post-traumatic stress disorder (e.g., Arntz et al., 2007), social phobia (e.g, Wild, Hackmann, \& Clark, 2007), and specific phobias (see for an overview Holmes, Arntz, \& Smucker, 2007; Hunt \& Fenton, 2007). During IR patients are asked to activate the memory of an aversive event and to mentally rescript it into another more neutral or positive image. For example, a traumatic memory of sexual abuse is rescripted by imagining that an adult intervenes and stops the abuser.

If the assumed mechanism of IR is correct, the advantage of IR over extinction is that the former directly acts upon the US presentation and therefore, can more easily generalize to other stimuli and environments. This is not the case with an extinction or exposure procedure. After extinction the CS is thought to have an ambiguous meaning; it predicts both the occurrence and the absence of the US. Especially the second-learned CS-noUS association is highly vulnerable to context changes after extinction (see for an overview Bouton, 2002, 2004). One robust phenomenon that indicates this vulnerability is the renewal effect. In the most common renewal paradigm, ABA renewal, acquisition of the CS-US association takes place in context $A$ and subsequently, the extinction is conducted in another context, context B. When the CS is then presented in the original acquisition context, context $A$, renewed responding is observed, indicating that the CS-US rather than the CS-noUS association is retrieved from memory (but see Nelson, del Carmen Sanjuan, Vadillo-Ruiz, Pérez, \& León, 2010). Indeed this $A B A$ renewal has been frequently observed in both animal (e.g., Thomas, Larsen, \& Ayres, 2003) and human fear conditioning studies (e.g., Effting \& Kindt, 2007; Vansteenwegen et al., 2005). Less renewed responding is expected after an IR intervention. Even if the original CS-US association is retrieved, no strong CR is expected as the US representation itself has been changed. To our knowledge, no study has been conducted that examined the influence of IR during extinction on renewal. Therefore, the main aim of the present study is to investigate the influence of IR during extinction on renewal using an ABA paradigm. It was hypothesized that changing the US representation during an extinction procedure should reduce renewed responding at test and devaluate the US.

\section{Method}

\subsection{Participants}

Seventy psychology students ( 20 males, 50 female) with a mean age of 22.02 years (range: $18.17-33.25$ and SD: 2.64 years) participated and received $1 \mathrm{~h}$ of course credit for their contribution. All participants signed a written informed consent before onset of the experiment and were pseudo randomly assigned to one of four experimental groups, with the restriction of an equal female/male distribution in each group (but, see inclusion criteria 2.4). The experiment was conducted in line with the declaration of Helsinki and approved by the local ethical committee (ECP-81).

\subsection{Apparatus}

\subsubsection{Computer task}

Two different pictures of a motorcycle (335 $\times 302$ pixels) and a car (522 $\times 211$ pixels) functioned as conditioned stimuli (CSs). An aversive IAPS picture (Lang, Bradley, \& Cuthbert, 2008) of a mutilated dead child (3051, valence rating: 2.30 , arousal rating: 5.62, $1024 \times 683$ pixels) served as unconditioned stimulus (US). The motorcycle was never followed by the US (CS-), whereas the car was consistently followed by the US ( $\mathrm{CS}+$ ) during acquisition. To control for stimulus order effects two different versions were used, with one version being the exact opposite of the other version (e.g. $\mathrm{CS}_{+}, \mathrm{CS}-, \mathrm{CS}-$ versus $\mathrm{CS}_{-}, \mathrm{CS}+, \mathrm{CS}+$, for all phases and conditions). The CSs were presented against one of two different background pictures $(1024 \times 683$ pixels): an abandoned residential area with a playing ground and a service station. These backgrounds functioned as contexts. The role of the pictures and backgrounds was not counterbalanced as we wanted the scene (see below) to be identical for all participants. Counterbalancing without changing the scene would have resulted in a less credible script during the extinction phase (see below, e.g. seeing the motorcycle at the residential area reminds you to make an appointment for the check-up of your own motorcycle). Pictures and backgrounds were presented via a computer screen. The US expectancy was measured in two ways: skin conductance response (SCR) and an online visual analogue scale (VAS). Electrodermal activity was continuously recorded with $\mathrm{AgCl}$ electrodes (1 $\mathrm{cm}$ diameter) attached to the volar surfaces of the medial phalanges of the first and second finger of the nondominant hand. Prior to attachment the participants cleaned their hands with tap water. A Brainvision professional Brainamp ExG Skin Conductor passed the signal to Brain Vision Analyzer 2.0 software. The VAS was presented on each CS presentation at the bottom of the screen. The indicator, defined by a vertical line of $1 \mathrm{~cm}$, could be set anywhere between the outer left (certainly no aversive picture) and outer right (certainly an aversive picture) end of the scale by clicking the left mouse button. The whole task was run on an IBM-compatible desktop computer and programmed with E-prime software (Psychology Software Tools, http://www.pstnet.com/).

\subsubsection{Questionnaires}

Three questionnaires were administered: the Dutch Beck Anxiety Inventory (BAI, Creamer, Foran, \& Bell, 1995), the Dutch State Trait Anxiety Inventory (STAI-DY, Van der Ploeg, 1982), and the Dutch version of the short version of the Bett's Questionnaire upon Mental Imagery (QUMI, Sheehan, 1967). The BAI is a self-report questionnaire that contains 21 items measuring state anxiety. Responses can be scored on a 0-3 scale ranging from "not at all" to "severely", giving a score between 0 and 63 . The STAI-DY contains two separate lists for state and trait anxiety. Each list contains 20 items and scoring is similar to the BAI (range per list 0-60).The QMI assesses 
imagery vividness and can be used to measure a person's general ability to create vivid images across a range of modalities. The questionnaire contains 35 items that can be scored on a 7-point Likert scale ranging from 1, "perfectly clear, as if it were real", to 7, "I think about it, but I cannot imagine it". In the QMI lower scores present a more vivid imagination (range 35-245). The BAI and STAI were administered to ensure that the trait and state level of anxiety were similar across the experimental groups as this can effect fear learning (see for a review, Bishop, 2007). The QMI was administered as individuals with high imagination ability might respond better to IR (but see Hunt \& Fenton, 2007).

\subsubsection{Ratings and interview}

Before and during the experiment the CSs and US were rated three times with Self-Assessment-Manikin scales (SAM, e.g., Bradley \& Lang, 1994). For each picture the experienced amount of pleasure (valence), arousal, and dominance were measured (scale 1-9). Pictures were printed out and rated with a pencil on paper SAM scales. After the experiment a short interview was conducted. In this interview the following topics were addressed: previous experiences with car-accidents, and the credibility and imaginability of the scripts used.

\subsection{Procedure}

After entering the room the participant was seated in a comfortable armchair. The participant signed an informed consent after reading general information about the experimental procedure. Subsequently, the participant was asked to fill out the BAI-DY and STAI (state and trait). Then the electrodes were attached and the experimenter started the computer task. The computer task consisted of a preconditioning phase, acquisition phase, extinction phase, and a renewal test. The experimental design is presented in Table 1 . The four groups in this experiment were: ABAir, ABAcont, ABAno, and AAAno. A and B symbolize the two different contexts (residential area and service station) during respectively, the acquisition, extinction, and renewal test. For all ABA groups acquisition and testing were conducted in context $A$ and extinction was carried out in context $B$. For the AAAno group acquisition, extinction, and testing all took place in context $A$. The ABAir received imagery rescripting (ir) instructions to devalue the US during the extinction phase, the ABAcont had to imagine a control script (cont) that did not invite to devalue the US during extinction, and the ABAno and AAAno received only extinction and no rescripting instructions (no). The combination of these four conditions allowed us to control for a general effect of imagination

Table 1

Experimental design.

\begin{tabular}{llll}
\hline Group & Acquisition & Extinction & Renewal test \\
\hline ABAir & Script accident & Imagery rescripting & \\
& $\mathrm{A}[\mathrm{CS}+] \rightarrow$ US & $\mathrm{B}[\mathrm{CS}+] \rightarrow$ noUS & $\mathrm{A}[\mathrm{CS}+] \rightarrow$ ? \\
& $\mathrm{A}[\mathrm{CS}-] \rightarrow$ noUS & $\mathrm{B}[\mathrm{CS}-] \rightarrow$ noUS & $\mathrm{A}[\mathrm{CS}-] \rightarrow$ ? \\
ABAcont & Script accident & Control rescripting & \\
& $\mathrm{A}[\mathrm{CS}+] \rightarrow$ US & $\mathrm{B}[\mathrm{CS}+] \rightarrow$ noUS & $\mathrm{A}[\mathrm{CS}+] \rightarrow ?$ \\
& $\mathrm{~A}[\mathrm{CS}-] \rightarrow$ noUS & $\mathrm{B}[\mathrm{CS}-] \rightarrow$ noUS & $\mathrm{A}[\mathrm{CS}-] \rightarrow ?$ \\
ABAno & Script accident & No rescripting & \\
& $\mathrm{A}[\mathrm{CS}+] \rightarrow$ US & $\mathrm{B}[\mathrm{CS}+] \rightarrow$ noUS & $\mathrm{A}[\mathrm{CS}+] \rightarrow ?$ \\
& $\mathrm{~A}[\mathrm{CS}-] \rightarrow$ noUS & $\mathrm{B}[\mathrm{CS}-] \rightarrow$ noUS & $\mathrm{A}[\mathrm{CS}-] \rightarrow ?$ \\
AAAno & Script accident & No rescripting & \\
& $\mathrm{A}[\mathrm{CS}+] \rightarrow$ US & $\mathrm{A}[\mathrm{CS}+] \rightarrow$ noUS & $\mathrm{A}[\mathrm{CS}+] \rightarrow ?$ \\
& $\mathrm{~A}[\mathrm{CS}-] \rightarrow$ noUS & $\mathrm{A}[\mathrm{CS}-] \rightarrow$ noUS & $\mathrm{A}[\mathrm{CS}-] \rightarrow ?$ \\
\hline
\end{tabular}

Note: $\mathrm{A}$ and $\mathrm{B}$ represent the two different contexts, CS + and $\mathrm{CS}-$ are the two conditioned stimuli, + followed by the US during the acquisition, - not followed by the US during the acquisition. Groups: ir indicates that imagery rescripting was used to devaluate the US, cont means a non-related rescripting assignment, and no that no rescripting was used (only extinction). Testing was conducted without the US. on extinction and renewal (ABAcont versus $A B A n o$ ), the additional effect of IR on mere extinction (ABAir versus ABAno group), and to ensure that renewal indeed occurred due to a switch in context after extinction (AAAno versus ABA groups).

\subsubsection{Pre-conditioning}

The preconditioning phase started with the SAM ratings of all stimuli: the two CSs (without background), the US, and the two backgrounds (SAM1). Each of these stimuli was printed out on paper and the participant was instructed to rate the valence (positive negative), arousal (high - low), and experienced dominance (low high) elicited by each picture. Then the experimenter started the computer task and an instruction screen appeared. In this instruction the participant was instructed to detect the contingencies between the pictures presented and the (non)occurrence of the aversive picture. Furthermore, a brief instruction about the use of the visual analogue scale (VAS) was presented. After pressing the space bar three practice trials were offered to familiarize the participant with the experimental procedure. Each trial started with a background picture of a patch of grass for $6-8 \mathrm{~s}$ (mean $7 \mathrm{~s}$ ). Against this background a picture of a ladybug was presented for $6 \mathrm{~s}$. Below this picture at the bottom of the screen the VAS was presented against a grey-coloured background. The participant was instructed to place the indicator by clicking the left mouse button. Only responses during the CSs were recorded. During the inter-trialinterval a black screen was presented for 4-6 s (mean $5 \mathrm{~s}$ ). The total duration of each trial was $18 \mathrm{~s}$, the CS-CS interval was $12 \mathrm{~s}$.

\subsubsection{Acquisition phase}

The acquisition phase was identical for all four groups and started with the description of the following scene (translated from Dutch):

Imagine that it is a Sunday morning, the weather is nice, and you decide to walk outside. It is early in the morning and quiet, you only see a boy playing outside with his football. A motorcycle passes and waves to the boy as he passes by. Then the ball rolls down the street and the boy wants to fetch it just as a car comes around the corner. The car hits the boy and to your horror the car does not stop but speeds of. You run to the boy, he is lying down the street and has severe head injuries. He does not react to your voice and you immediately reach for you phone to dial 911. As you search for your phone you remember that you left it at home in the charger. You shout for help but nobody seems to hear you. The boy stops breathing and dies in your arms.

After reading the instructions the participant was asked to close his/her eyes and instructed to imagine the scene as vividly as possible. On directions of the participant the experimenter started the acquisition trials. Each trial started with the presentation of the background picture, a residential area with a playing ground (context $A$ ). After $4-8 \mathrm{~s}$ (mean $6 \mathrm{~s}$ ) the CS picture and VAS were placed against this background. The CS and VAS remained visible for $6 \mathrm{~s}$ and the participant could indicate on the VAS whether the US was expected or not. In case of the picture of the car (CS+) the US (IAPS picture of mutilated dead child, $2000 \mathrm{~ms}$ ) followed immediately after offset of the CS. In case of the motorcycle (CS-) no US followed, but the inter-trialinterval was extended by $2000 \mathrm{~ms}$. The inter-trial-interval consisted of the presentation of a black screen and varied between 4 and 8 (mean 6) seconds. The total duration of each trial was $20 \mathrm{~s}$, the CS-CS interval was $14 \mathrm{~s}$. Each CS was presented 4 times, resulting in a total of 8 acquisition trials. CSs were pseudo randomly mixed with the restriction that a CS was never presented more than two times in a row. After the last acquisition trial a screen popped-up and asked the participant to give a second SAM rating of all stimuli (SAM2). After finishing these ratings the experimenter started the extinction phase. 


\subsubsection{Extinction phase}

For the ABAir, ABAcont, and ABAno the background scenery switched to the service station (context B). For the AAAno the background remained the same that is the residential area with the playing ground. The ABAir group received instructions for imagery rescripting of the US, the ABAcont received a control imagination assignment, the $A B A n o$ and $A A A n o$ groups received no imagination assignment. For the ABAir group the instruction was as follows:

Imagine the following situation. The boy plays in the residential area; a motorcycle passes by and waves. The ball rolls down the street. Just as the boy fetches the ball a car comes around the corner and hits the boy. The car speeds off. You run to the boy and see that he has severe injuries. You reach for your phone to dial 911. This time the telephone is in your pocket. The 911 emergency team gives your instructions to stop the bleeding and the ambulance arrives just in time. The next day you visit the hospital. The doctor assures you that in time the boy will be fine. The parents of the boy thank you for your adequate reaction, without your help the story would have ended differently. The boy smiles as you hand over a comic book.

(Next screen on directions of the participant): During the next part of the experiment you will again see pictures of the car and motorcycle. Please keep on indicating whether you expect the aversive picture or not.

After a car picture we want you to close your eyes and imagine the complete scene in which you save the boy. Start this imagination as soon as the black screen is presented. Take your time and press spacebar at the moment that the entire scene is as clear and detailed as possible. You do not need to imagine this scene after the presentation of the motorcycle.

For the ABAcont group the following instructions appeared:

Imagine the following situation. A week later you walk by a service station and you see the car that was involved in the accident. You immediately remember the accident and the feelings of helplessness of not being able to save the boy's life. However, the car also reminds you that you need to bring your own car to the service station for the periodic motor vehicle test. Your car is old and not in a particular good shape and you wonder if the car will pass the test. You are quite attached to your small red vehicle and it has served you for more than 2 years. You pick up your phone and make an appointment with the service station for this afternoon. The next day you go to the service station and to your joy the car passed the periodic motor vehicle test without any problems.

(Next screen on directions of the participant): During the next part of the experiment you will again see pictures of the car and motorcycle. Please keep on indicating whether you expect the aversive picture or not.

After a car picture we want you to close your eyes and imagine the complete scene in which you bring your car to periodic motor vehicle test. Start this imagination as soon as the black screen is presented. Take your time and press spacebar at the moment that the entire scene is as clear and detailed as possible. You do not need to imagine this scene after the presentation of the motorcycle.

Note that the control script also included using the telephone and included the feelings of helplessness and relief (car passed the test) in order to control for possible mood influences on learning (Nadler, Rabi, \& Minda, 2010). For all four groups the last screen before the extinction indicated that the relationship between the pictures might have been changed, and if so, instructed the participants to change their ratings accordingly.
After the instruction the motorcycle and car were each presented 6 times, resulting in a total of 12 trials. During the extinction phase no US was presented. Stimulus order was pseudo random with the restriction that a stimulus was not presented more than two times in succession. For the $\mathrm{CS}+$ inter-trial-interval the ABAno and AAAno participants were each linked to the inter-trial-interval time of an IR participant (yoked control). All other details were identical to the acquisition phase. The renewal test automatically started after the last extinction trial.

\subsubsection{Renewal test}

This test started with a short instruction for the ABAir and ABAcont groups. They were explicitly instructed to no longer use IR after stimulus presentations. This was done to ensure that a diminishment in renewal was not due to an association between the rescripting instructions and the non occurrence of the US. For all participants the residential area (context A) served as background. The two CSs were each presented twice with the restriction that both $\mathrm{CS}+$ and CS- occurred in the first two trials. During the renewal test no US was presented. Further details were identical to that of the acquisition phase. After finishing the last trial, the participant was asked to rate all stimuli for the last time (SAM3). The electrodes were removed and participants were requested to fill in the QMI. The experiment finished with a short interview about the credibility of the scenes, the ability to imagine the scripts, and questions concerning possible car accident experiences in the past.

\subsection{Criteria}

As in our previous studies on renewal, the intention was to analyze only the data of participants that mastered the task (Dibbets, Havermans, \& Arntz, 2008; Dibbets \& Maes, 2011). The a priori criteria for selection were: (1) On the last acquisition trial scores on the VAS scale for CS + needed to be at least 75\%, indicating clear expectancy of the US; (2) Scores on the last acquisition trial of CS - needed to be $25 \%$ or less, indicating that no US was expected; and (3) On the last extinction trial ratings of both CSs should be $25 \%$ or less, indicating successful extinction. These criteria were set a testing for renewal is redundant in the absence of fear acquisition and extinction. The number of participants in each condition that successfully mastered the task based on these criteria was set at 12 (i.e. 48 participants in total). However, the number of participants tested in order to include these 12 participants, strongly deviated between the four experimental conditions. The total number of participants in each condition was: 25 in the ABAir condition, 16 in the ABAcont condition, 14 in the ABAno condition, and 15 in the AAAno condition. Within the ABAir condition, 11 participants did not meet the extinction criteria. Selection of only the 12 participants in the ABAir criteria would result in a biased sample, as more than half of the participants of this groups would be discarded (other conditions: $<25 \%$ excluded). Additionally, as the weaker extinction during the application of IR might be crucial for assessing its effectiveness, we decided to include the data of all 70 participants, resulting in an unequal distribution of participants across conditions. This gives the additional advantage that we could more reliably assess the influence of imagery capacities as reported on IR (see below).

\subsection{QMI scores}

To assess the influence of imagery ability on extinction and renewal, the participants of the ABAir group were subdivided in a 'good', 'moderate', or 'poor' imagers group (Merckelbach, De Jong, \& Arntz, 1991). The lower 33\% of the QMI distribution was labelled as the 'good' imagers group ( $n=8$, range $40-79)$, the middle $33 \%$ 
was labelled as the 'moderate' imagers group ( $n=8$, range 87-97), and the top $33 \%$ as the 'poor' imagers ( $n=9$, range $106-198)$. This subdivision was made as we expected that good imagers would outperform poor imagers in mentally devaluing the US, resulting in a weaker CR during the extinction phase and less renewal at test.

\subsection{Response definition and data reduction of SCR}

\subsubsection{Ratings and renewal}

The amount of renewal was calculated by subtracting the ratings of $\mathrm{CS}+$ on the last extinction trial, trial 6, from the ratings on the first trial of the renewal test. A similar difference score was calculated for CS- (see also, Dibbets et al., 2008).

\subsubsection{Skin conductance responses}

Skin conductance responses (SCR) to the conditioned stimuli were analyzed using the computer program Ledalab (V3.2.4). Data were imported in Ledalab from Brain Vision Analyzer and preprocessed (Manual smoothing, 8 Gauss window, down sampling to $10 \mathrm{~Hz}$ ). Artifacts were manually traced and corrected using a spline interpolation. Next a continuous decomposition analysis was run, optimizing the fit and reducing the error of the model (Bateman functions comprising onset, amplitude, tau 1 and tau 2 parameters). Next eventrelated activation based on the event-locked markers was calculated by using the largest deflection in conductance between 900 and $4000 \mathrm{~ms}$ after stimulus onset (First Interval Response, FIR) with a minimum response of $.02 \mu \mathrm{s}$. Amplitudes were subjected to a square root transformation for normalization (Dawson, Schell, \& Filion, 2007).

For each participant, mean amplitudes on the CS + and CS - were calculated for 5 blocks: all four acquisition trials (acq), the first three and last three extinction trials (ext1 and ext2, respectively), and the two renewal test trials (ren). For calculation of the renewal (difference) score of these mean SCRs see Ratings and Renewal.

\subsection{Statistical analyses}

The total score on each questionnaire, the US expectancy ratings on the VAS, the SAM ratings, and the SCR were analyzed using parametric tests, GLM repeated measures and ANOVAs. Each CS was analyzed separately for the US expectancy data. Bonferroni corrections were used by adjusting the rejection criterion in case of multiple, planned or pairwise comparisons. In case of violations of sphericity, GreenhouseGeisser corrections were made. Possible differences between groups in the distribution of gender were analyzed nonparametrically. The standard rejection criterion was set at $p<.05$ throughout.

\section{Results}

\subsection{Demographic variables and questionnaire data}

Table 2 displays the demographic information and the total scores on the BAI, STAI-DY, and QMI, per group. No significant differences were observed regarding age, questionnaire scores, $F s(3,66)<1.81$, $p s>.15$, or gender distribution, $\chi^{2}=.57, p=.90$.

\subsection{US expectancy ratings}

\subsubsection{Acquisition}

3.2.1.1. CS + ratings. The mean expectancy ratings of $\mathrm{CS}+$ and $\mathrm{CS}-$ are presented in the top panel of Fig. 1. A GLM repeated measure with trial (1 through 4) as within-subjects measures and group (ABAir, ABAcont, ABAno, and AAAno) as between-subjects factor was used to analyze the ratings of the acquisition phase. This analysis revealed a main effect of trial, $F(1.77,117.36)=46.80$, $p<.001$, indicating an increase in the US expectancy across the acquisition phase. No other effects were observed, $F \mathrm{~s}<1$.

3.2.1.2. CS- ratings. A similar GLM was run on the CS- data. This analysis revealed a main effect of trial, $F(2.57,169.59)=24.66$, $p<.001$, indicating a decrease across trials, and a main effect of group, $F(3,66)=2.86, p<.05$. No trial $\times$ group interaction was observed, $F<1$. Multiple comparisons indicated that the AAAno group displayed, overall, lower $\mathrm{CS}$ - ratings than did the ABAcont group, $p<.05$, no other group differences were observed, $p s>.12$. This group difference was not considered to be a problem as the CS - expectancy ratings on trial 4 did not differ between the four groups, oneway ANOVA, $F<1$, indicating a similar offset of the acquisition phase.

\subsubsection{Extinction}

3.2.2.1. CS + ratings. The extinction ratings are displayed in Fig. 1, bottom panel. The extinction expectancy ratings were analyzed in the same way as the acquisition data using a GLM repeated measures with trial ( 1 through 6 ) as within-subjects measures and group as between-subjects factor. This analysis revealed a main effect trial, $F(3.52,232.21)=59.51, p<.001$, a trial $\times$ group interaction, $F(10.56,232.21)=2.64, p<.05$, and a main effect of group, $F(3,66)=3.06, p<.05$. Multiple comparisons indicated that, overall, the ABAir group displayed higher $\mathrm{CS}+$ ratings than did the ABAno group, $p<.05$. No other group differences were observed, ps $>.20$.

The interactions observed were analyzed further using separate oneway ANOVAs on each trial. Group differences were observed for trial $3,4,5$, and $6, F s(3,66)>3.03, p s<.05$. Multiple comparisons revealed that on trial 3 the ABAir group had higher $C S+$ ratings than did the AAAno group, $p<.05$, a marginally significant difference was observed between the ABAir and ABAno group, $p=.074$. On the last extinction trial, trial 6 , the ABAir group rated the $C S+$ higher than did the ABAno group, $p<.05$. No other group differences were observed, $p s>.09$.

It is important to notice that for all groups CS+ ratings significantly declined across trials, GLM repeated measures, Fs $>4.60$, $p s<.05$, indicating that in each group extinction, at least partially, took place.

3.2.2.2. CS - ratings. The GLM repeated measures of the CSratings revealed a main effect of trial, $F(2.02,133.29)=29.96$, $p<.001$, a trial $\times$ group interaction, $F(6.06,133.29)=2.57, p<.05$, but no main effect of group, $F(3,66)=1.10, p=.36$.

Table 2

Demographic information and mean scores (standard deviation) on the questionnaires.

\begin{tabular}{|c|c|c|c|c|c|c|}
\hline \multirow[t]{2}{*}{ Group } & \multirow[t]{2}{*}{ Age } & \multirow[t]{2}{*}{$\mathrm{m} / \mathrm{f}$} & \multirow[t]{2}{*}{ BAI } & \multicolumn{2}{|l|}{ STAI-DY } & \multirow[t]{2}{*}{ QMI } \\
\hline & & & & State & Trait & \\
\hline ABAir & $21.91(2.35)$ & $7 / 18$ & $31.28(7.62)$ & $33.72(7.10)$ & $36.52(9.34)$ & $90.88(30.05)$ \\
\hline ABAcont & $21.78(3.80)$ & $5 / 11$ & $29.13(6.05)$ & $30.63(4.54)$ & $34.31(7.25)$ & 102.63 (28.09) \\
\hline ABAno & $22.08(2.17)$ & $3 / 11$ & $30.21(5.01)$ & $32.93(10.03)$ & 35.64 (9.59) & $84.50(28.12)$ \\
\hline AAAno & $22.39(2.15)$ & $5 / 10$ & $27.93(4.48)$ & $29.47(6.24)$ & $31.53(7.28)$ & $81.67(19.40)$ \\
\hline
\end{tabular}




\section{Acquisition CS+}

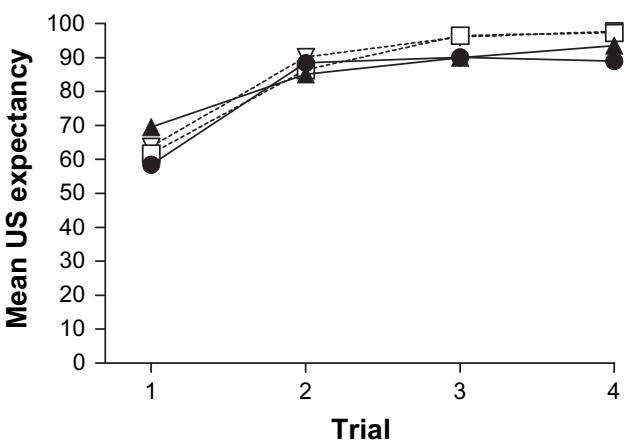

Extinction CS+

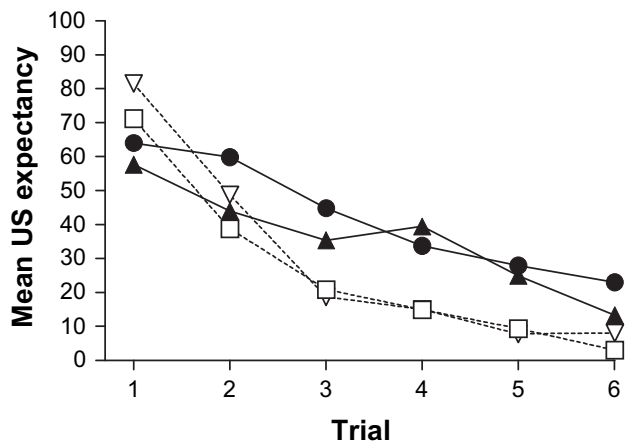

Acquisition CS-

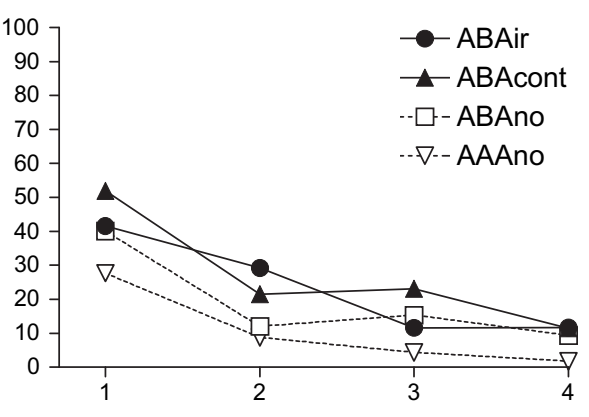

Extinction CS-

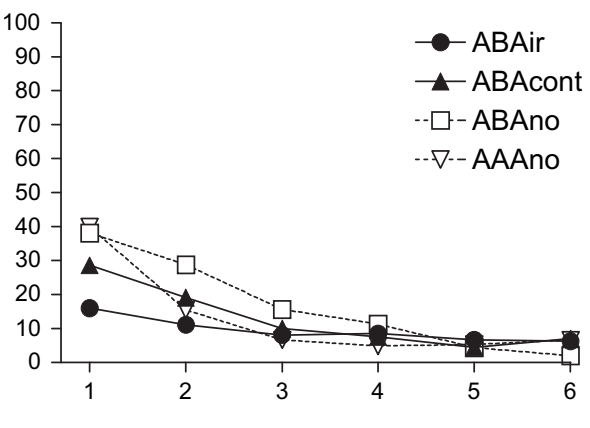

Fig. 1. Top panel: mean ratings per group of $\mathrm{CS}+$ and $\mathrm{CS}-$ across the acquisition phase. Bottom panel: mean ratings per group of $\mathrm{CS}+$ and $\mathrm{CS}-$ across the extinction phase.

Separate oneway ANOVAs on each trial revealed a group effect on trial $1, F(3,66)=3.13, p<.05$, and a marginally significant effect on trial $2, F(3,66)=2.67, p=.055$. Multiple comparisons revealed that the ABAir group tended to give lower ratings on the first CSpresentation compared to the AAAno group, $p=.06$. On trial 2 the ABAir group rated CS- significantly lower than did the ABAno group, no other differences were observed, $p s>.11$.

Summarized, the acquisition data indicated that $\mathrm{CS}+$ ratings increased and CS- ratings decreased across trials. At the offset of the acquisition phase no group differences were observed. The extinction data indicated that both $\mathrm{CS}+$ and $\mathrm{CS}$ - ratings decreased as extinction progressed and that the rate of extinction was slowest for the ABAir group with higher $\mathrm{CS}+$ ratings for the ABAir group compared to the ABAno group at the offset of the extinction phase.

\subsubsection{Renewal}

As mentioned before, renewal was calculated by subtracting the ratings on the last extinction trial from the ratings on the test trial. This renewal score is an indicator for the increase (or decrease) in ratings due to a change in context and, at the same time, corrects for group and individual differences at the offset of the extinction phase. The renewal scores are depicted in Fig. 2, with higher scores representing more renewal.

3.2.3.1. CS + change. A oneway ANOVA was run on the renewal scores of the $\mathrm{CS}+$ in the four groups. This analysis revealed a main effect of group, $F(3,66)=20.89, p<.001$. Multiple comparisons indicated that the AAAno group showed less renewal than the remaining three groups, $p s<.001$. Less renewal was observed in the ABAir group compared to the ABAno group, $p<.05$, no other group differences were observed, $p s>.24$.
3.2.3.2. CS - change. A similar analysis was run for the CS- scores. This analysis revealed a main effect of group, $F(3,66)=3.15, p<.05$. Multiple comparisons only revealed to marginally significant differences: the AAAno group displayed less increase in responding than did the ABAcont and ABAno groups, $p s<.065$. No other group differences were observed, $p s>.37$.

3.2.3.3. Additional CS+ analysis. Although the abovementioned renewal score does correct for extinction offset differences, it does not correct for the influence of this differential offset on the CS+ rating at test. We therefore decided to use the US expectation at the

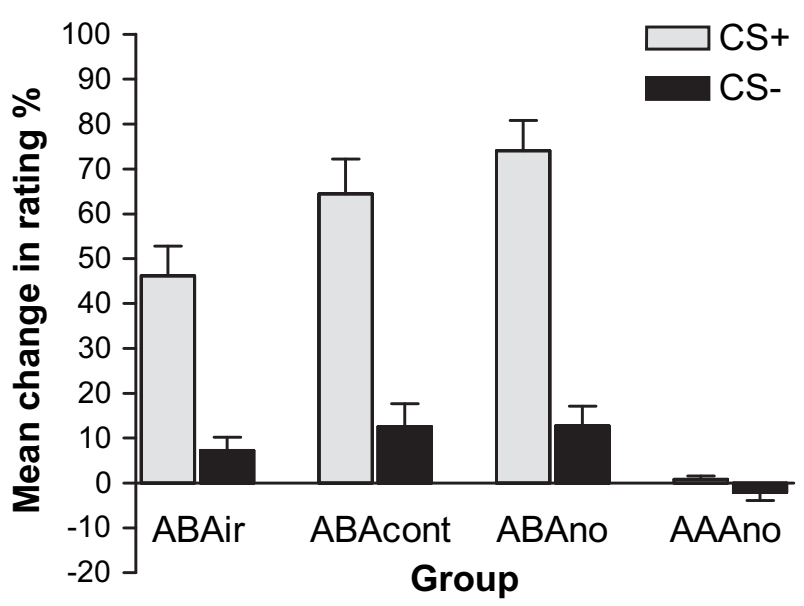

Fig. 2. Mean increase in ratings and SEMs on CS + and CS- during the renewal test compared to the extinction phase, with higher scores representing more renewal. 
last extinction trial as a covariate for the US expectancy at test. Exploration of the data revealed that there was an interaction between covariate an experimental condition, and distributions were multivariate non-normal. As a result we used an ordinal analogue of analysis of covariance, ordinal regression (PLUM module in SPSS) with a model containing experimental condition (AAAno, ABAno, ABAir, and ABAcont), US expectancy at the last extinction trial, and their interaction as predictors, and the CS+ renewal test ratings as dependent variable. Differences between the ABAir and the other conditions were tested. This analysis revealed significant effects for the whole model, $\chi^{2}(7)=73.21$, $p<.001$, for the ABAir versus ABAcont contrast, Wald $=4.86$, $p<.05$, for the ABAir versus AAAno contrast, Wald $=21.10, p<.05$; but not for the ABAir versus ABAcont contrast, Wald =1.83, $p=.18$. The covariate main effect was not significant, Wald $=1.38, p=.24$, thus there was no main effect of level of US expectancy at the last extinction trial on level of US expectancy at test. However, the relationships of covariate with dependent variable were significantly different between ABAir and ABAno group, and between the ABAir and AAAno group, Walds $>5.41, p s<.05$. The results of this analysis are depicted in Fig. 3. In sum these results were highly similar to the renewal score analysis, indicating that the findings were not an artefact of ABAir having higher US expectancy ratings at the end of the extinction phase.

\subsection{Skin conductance response}

The SCR data of two participants were not recorded due to equipment failure (one participant of the ABAir and one of the AAAno group). Therefore, a total of 68 participants was included for SCR analyses.

\subsubsection{US and CS responses}

To assess the possibility of the IAPS picture to serve as US, a GLM repeated measures was carried out with the first presentation of each stimulus (US, CS+, and CS-) as within-subjects factor, and group (ABAir, ABAcont, ABAno, and AAAno) as between-subjects factor. This analysis allows examining the effect of the aversive US and the CSs (non-predictive on the first occurrence) on the SCR. The analysis revealed a main effect of stimulus, $F(1.54$, $98.35)=7.30, p<.005$, but no effect for group, $F<1$. Pairwise comparisons indicated that the US received larger SCR (mean: $3.48 \mu \mathrm{S}, \mathrm{SD}: .89$ ) than did CS+ (mean: $1.58 \mu \mathrm{S}, \mathrm{SD}: .39$ ) and CS-

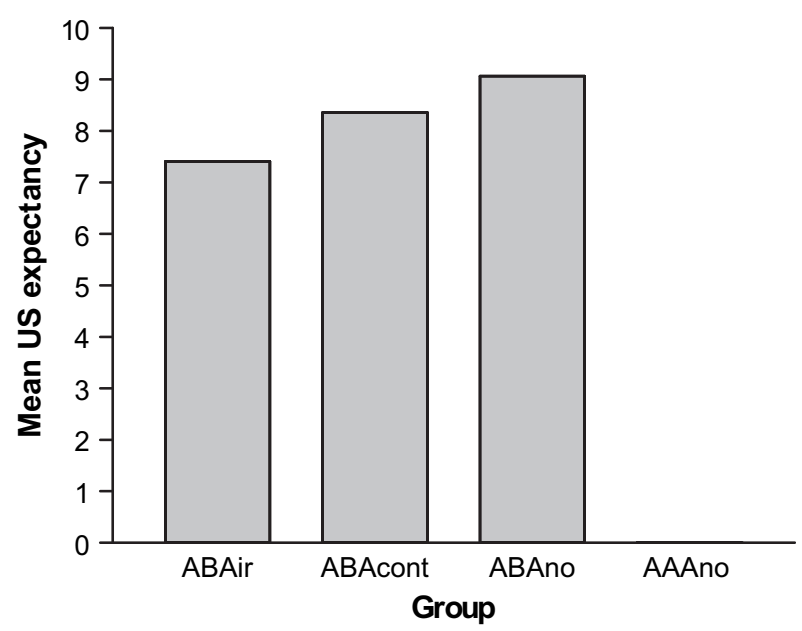

Fig. 3. Results of the ordinal regression. US expectancies on CS + are corrected for the last extinction trial and the AAAno group functions as reference group. (mean: $1.35 \mu \mathrm{S}, \mathrm{SD}: .49$ ), ps $<.05$, but no difference was observed between the two CSs, $p=1.00$. This indicates that, as expected, the US resulted in larger SCR than did CS+ or CS - before establishment of the CS-US association.

\subsubsection{Acquisition}

A GLM repeated measures with stimulus type (CS+ and $\mathrm{CS}-$ ) as within-subjects factor and group (ABAir, ABAcont, ABAno, and AAAno) as between-subjects factor was used to analyze the SCR of the acquisition phase. This analysis revealed a main effect of stimulus type, $F(1,64)=7.45, p<.01$, but no significant stimulus $\times$ group interaction or group effect, $F s<1$. This indicates that the SCR pattern was similar in all groups with larger responses on CS+ (mean: .59 $\mu$ S, SD: .66), than on CS- (mean: .47 $\mu S$, SD: .62), indicating successful discrimination learning.

\subsubsection{Extinction}

A GLM repeated measures with trial block (ext1 and ext2) and stimulus type ( $\mathrm{CS}+$ and $\mathrm{CS}_{-}$) as within-subjects factors and group as between-subjects factor was carried out to analyze the SCR of the extinction phase. This analysis only revealed a main effect of stimulus type, $F(1,64)=5.72, p<.05$, no other effects were observed, $F \mathrm{~s}<2.55$, $p \mathrm{~s}>.11$. The effect of stimulus type indicated that, overall, the SCR on CS+ (mean: .44 $\mu$ S, SD: .64) was larger than on CS- (mean: $.32 \mu \mathrm{S}, \mathrm{SD}: .42$ ), but that this response did not decline across trial blocks.

\subsubsection{Renewal}

Despite the lack of evidence for extinction, possible renewal was examined by subtracting the SCR of the last extinction block from the mean SCR of the renewal test. The mean difference score of CS+ and $\mathrm{CS}$ - were -.05 $\mu \mathrm{S}$ (SD: .56) and $.01 \mu \mathrm{S}$ (SD: .42), respectively. Oneway ANOVAs with the difference scores of CS + and CS - as dependent variables and group as factor were carried out and did not reveal any effect, $F s<1$.Subsequent one-sample t-tests revealed that the difference scores did not significantly differ from zero, $t$ s $<1$, indicating that no renewal was observed.

\subsection{QMI scores}

\subsubsection{Extinction}

3.4.1.1. CS + ratings. Fig. 4 displays the mean ratings during extinction on $\mathrm{CS}+$ for the good, moderate and poor imagers of the ABAir group. Note that no differences between these three groups were observed at the end of the acquisition phase (CS+ and $\mathrm{CS}-$ ), oneway ANOVAs, Fs $<1$. A GLM repeated measures with trial (1

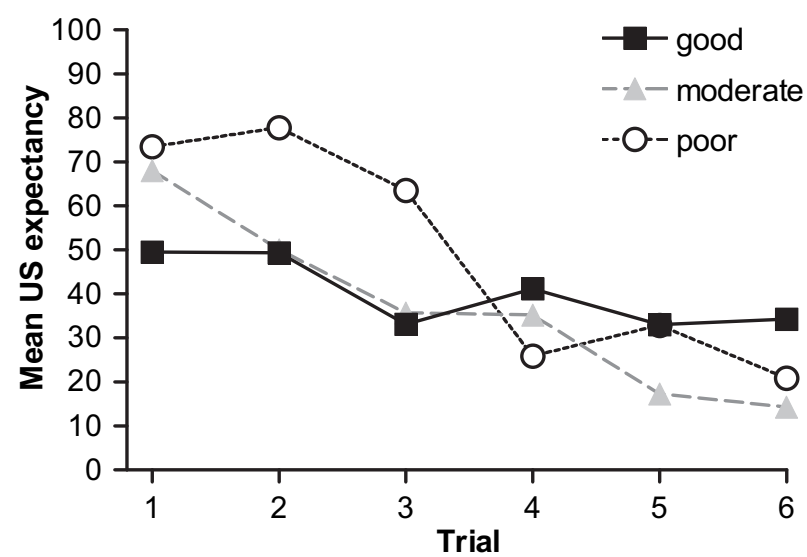

Fig. 4. Mean US expectancy during the extinction for the good, moderate, and poor imagers. 
through 6) as within-subjects factor and group (good, moderate, and poor) as between-subjects factor was carried out. This analysis yielded a main effect of trial, $F(3.21,70.56)=13.64, p<.001$, and a trial $\times$ group interaction, $F(6.42, .56)=2.35, p<.05$. No main effect of group was observed, $F<1$. Separate ANOVAs indicated that the interaction observed was not caused by a discrepancy in group differences on the extinction trials. None of the ANOVAs revealed a significant effect of group, $F s(2,22)<2.69$, $p s>.09$. Separate GLM repeated measures with trial as within-subjects factor of each group indicated that the trial $\times$ group interaction was caused by a decrease in ratings across trials for the moderate and poor imagers, $F s>8.84, p s<.005$, and the absence of such a decrease in the good imagers group, $F<1$.

3.4.1.2. CS - ratings. A similar analysis was run for CS - . This analysis revealed no main effects or interaction effect, $F s<1.85$, $p s>.17$.

\subsubsection{Renewal}

The effect of imaging capability on renewal was examined using oneway ANOVAs. In these analyses the renewal difference scores on $\mathrm{CS}+$ and CS - served as dependent variables and group (good, moderate, and poor imagers) as factor. These analyses did not reveal any effect of group on the amount renewal, $F s<1$.

\subsection{SAM ratings}

Because many participants reported problems with the interpretation of SAM dominance rating, we decided not to analyze these dominance ratings. No problems were expressed concerning the valence and arousal ratings (see Table 3 ). For sake of brevity the SAM ratings of the backgrounds were omitted.

\subsubsection{US ratings}

Two separate GLM repeated measures analyses were run to assess the change in US valence and arousal across the experiment. The three SAM ratings (before onset of the experiment, after the acquisition phase, and after the renewal test) served as withinsubject factor and group (ABAir, ABAcont, ABAno, and AAAno) functioned as between-subject factor. These analyses indicated that both the valence and arousal changed across the experiment, $F s>5.89, p s<.005$. Additionally, a SAM rating $\times$ group interaction was observed for US valence, $F(5.66,124.55)=2.48, p<.05$. No other effects were observed, $F s<1.76$, $p s>.16$. Multiple comparisons indicated that the US evoked more arousal after the acquisition (SAM2) than it did after the renewal test (SAM3), $p<.001$. The US was valued as more negative after the acquisition than it was on the initial and final rating, $p s<.05$.

The valence rating $\times$ group interaction was caused by the decrease in negative value of the US from SAM2 to SAM3 in the ABAir group, paired comparisons, $p<.05$, no such change in US value was observed in the other groups, $p s>.22$. This decrease indicates that the US was devalued (less negative) after the acquisition in the ABAir group, but not in the other groups.

\subsubsection{CS ratings}

Two separate GLM repeated measures analyzed the CS+ and CSarousal and valence ratings across the experiment. The CS+ analysis revealed that both the amount of arousal and the valence changed as testing progressed, $F \mathrm{~s}>57.93$, $p$ s $<.001$. A SAM rating $\times$ group interaction was observed for the CS+ valence, $F(5.17,113.64)=2.92$, $p<.05$. Pairwise comparisons revealed that for both arousal and valence all three ratings moments differed from each other, $p \mathrm{~s}<.001$. The amount of arousal elicited by the $\mathrm{CS}+$ from high to low can be summarized as follows: SAM2 > SAM3 > SAM1. Similarly, the CS+ valence ratings from negative to more positive can be ordered as: SAM2 $>$ SAM3 $>$ SAM1. The SAM rating $\times$ group interaction was caused by the initial group difference in valence rating of $\mathrm{CS}+$ at the onset of the experiment, $F(3,66)=3.68, p<.05$. Pairwise comparisons revealed that the $A B A c o n t$ group gave a more negative rating than did the ABAir group. This was not considered to be a problem as no group differences were observed after the acquisition on SAM2, $F<1$.

The CS - analysis revealed a main effect of arousal and valence, $F s>3.32$, ps $<.05$. No interactions or group effects were observed, $F s<1.31$, ps $>.26$. The amount of arousal decreased and the CSwas rated as more positive as the experiment progressed. Pairwise comparisons indicated that less arousal was reported on the last than the first CS - rating, $p<.05$.

\subsection{Interview}

The results of the interview indicated that none of the participants had previous experiences with (severe) car-accidents and that the script (both control and IR) was credible and imaginable.

\section{Discussion}

The present study is the first that examined whether devaluation of the US, by adding imagery rescripting (IR) during extinction,

Table 3

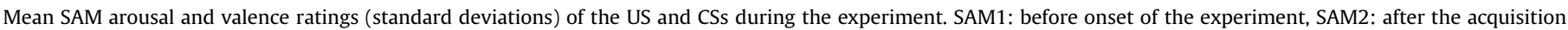
phase, SAM3: after finishing the experiment. Note that lower arousal scores indicate more arousal and that lower valence scores indicate a more positive valence.

\begin{tabular}{|c|c|c|c|c|c|c|}
\hline \multirow[t]{2}{*}{ Group } & \multicolumn{3}{|l|}{ US Arousal } & \multicolumn{3}{|l|}{ US Valence } \\
\hline & SAM1 & SAM2 & SAM3 & SAM1 & SAM2 & SAM3 \\
\hline ABAir & $2.96(1.37)$ & $2.40(1.19)$ & $2.80(1.58)$ & $8.28(1.34)$ & $8.56(.71)$ & $7.76(1.09)$ \\
\hline ABAcont & $3.69(1.82)$ & 3.13 (1.93) & $3.88(2.03)$ & $7.88(1.54)$ & $8.56(.073)$ & $8.50(.073)$ \\
\hline ABAno & $3.14(1.88)$ & $2.79(2.29)$ & 4.00 (2.69) & $8.50(.94)$ & $8.64(.75)$ & $8.36(.84)$ \\
\hline \multirow[t]{3}{*}{ AAAno } & $3.60(1.84)$ & $3.60(1.40)$ & $4.27(1.62)$ & $8.27(.88)$ & $8.53(.83)$ & $8.20(.86)$ \\
\hline & $\mathrm{CS}+$ Arousal & & & CS + Valence & & \\
\hline & SAM1 & SAM2 & SAM3 & SAM1 & SAM2 & SAM3 \\
\hline ABAir & $7.60(1.71)$ & $4.08(1.94)$ & $5.48(1.90)$ & 3.56 (1.69) & $6.76(1.30)$ & $5.64(1.73)$ \\
\hline ABAcont & 7.44 (1.79) & $4.81(2.01)$ & $6.25(1.61)$ & $5.19(1.72)$ & $6.19(1.64)$ & $5.38(.81)$ \\
\hline ABAno & $7.86(1.41)$ & $5.14(2.03)$ & $6.43(1.51)$ & $3.50(1.91)$ & $6.50(1.70)$ & $4.86(1.35)$ \\
\hline \multirow[t]{3}{*}{ AAAno } & $8.33(.82)$ & $5.67(2.06)$ & $7.07(1.62)$ & $3.67(1.54)$ & 6.73 (1.39) & $5.00(1.07)$ \\
\hline & $\mathrm{CS}-$ Arousal & & & CS- Valence & & \\
\hline & SAM1 & SAM2 & SAM3 & SAM1 & SAM2 & SAM3 \\
\hline ABAir & $6.72(2.21)$ & $7.08(1.50)$ & $7.28(1.72)$ & $3.72(1.57)$ & $3.52(1.33)$ & 3.88 (1.39) \\
\hline ABAcont & $6.94(2.02)$ & $7.19(1.76)$ & $7.44(1.75)$ & $4.13(1.41)$ & $3.94(1.65)$ & $3.81(1.33)$ \\
\hline ABAno & $7.50(1.70)$ & $7.86(1.23)$ & $8.07(1.00)$ & $4.00(1.75)$ & $3.00(1.80)$ & 3.14 (1.79) \\
\hline AAAno & $7.07(1.58)$ & $7.60(1.60)$ & 7.80 (1.37) & $3.60(1.68)$ & $3.40(1.81)$ & $3.53(1.41)$ \\
\hline
\end{tabular}


resulted in less renewal of an extinguished CR than mere extinction. The results indicate that all groups readily learned to differentiate between the CS that predicted the occurrence of the US (i.e. $\mathrm{CS}+$ ) and the $\mathrm{CS}$ that predicted its absence (i.e. $\mathrm{CS}-$ ) during the acquisition phase in context $A$. Next, the differential expectancy of the US was successfully extinguished in either a different context, context $\mathrm{B}$, or in the acquisition context $\mathrm{A}$. The expectancy reoccurred as participants re-entered the acquisition context $A$, but not if they remained in the extinction context, indicative of $A B A$ renewal. Most importantly, the amount of renewal was smaller in the ABAir group than it was in the ABAno group, indicating that adding IR during extinction indeed resulted in less renewal than mere extinction. Additionally, only in the ABAir group the US was devalued after the acquisition phase, resulting in a less negative representation of the US after the test (large effect, $\eta_{\mathrm{p}}^{2}=.27$ ).

The re-emergence of the conditioned response by returning to the acquisition context concords with other studies that examined ABA renewal in humans (e.g., Dibbets et al., 2008; Effting \& Kindt, 2007; Vansteenwegen et al., 2005). This indicates that the paradigm used enables the examination of renewed responding due to a switch in context after extinction. Also the devaluation of the mental representation of an aversive event, US, through imagery rescripting is in line with previous, clinical, studies (e.g., Hunt \& Fenton, 2007; Wild et al., 2007). As in these studies, rescripting resulted in a less negative rating of the aversive stimulus or event.

The results also accord with the model presented by Davey (1997). In this model the strength of the CR can be modulated by changing the mental representation of the US, even if the US itself is not presented. The devaluation of the US through mental IR indeed resulted in a less negative rating, indicative of a change in the mental US representation, and in less renewed responding to the CS after a context change. This devaluation did not occur in the groups that did not receive US devaluation instructions, but also underwent an extinction procedure. This indicates that not the CS alone presentations altered the US presentation, but that probably mentally rewriting the US enabled this devaluation.

Although the above paragraphs seem to imply that IR has only beneficial effects, this is not the case. One of the observations in the current study was that IR resulted in a slower extinction rate of the $\mathrm{CS}+$, with higher US expectancy ratings at the end of the extinction phase compared to the extinction only group (ABAno). This slower extinction cannot be explained by the lower onset of the extinction phase of the ABAir group as this group did not significantly differed from the other groups on the first CS + trial. An alternative, more likely, explanation is that mentally rehearsing the CS-US relation during rescripting resulted in a slower extinction rate. Several experiments have demonstrated that the mental presentation of the US on CS presentation can retard extinction (see for an overview Dadds et al., 1997). If this is the case on our experiment, it comes as no surprise that the extinction rate was slowest in the ABAir group. This group was not only encouraged to devalue the US during the extinction period, but also to relive the entire scene that included the CS-US pairing. Especially this CS-US rehearsal might have resulted in the (partial) maintenance of this association during the extinction phase. As mentioned in the review of Dadds et al. (1997), it is likely that participants with superior imagery ability should display the slowest extinction rate. This was indeed what we observed, during extinction the US expectancy ratings of the 'poor' and 'moderate' imagers declined across trials whereas no such decrease was observed in the 'good' imagers group. This absence of a decrease in the 'good' imagers group could not be explained by group differences at the end of the acquisition or onset of the extinction phase, $F s(2,24)<1.19$, ps $>.32$. An alternative explanation is that 'good' imagers were more distracted from the conditioning task, resulting in slower extinction regardless of the contents of the mental activity. This seems not to be the case as a similar subdivision into 'good', 'moderate', and 'poor' imagers of the group that received a control imagination assignment did not reveal differential extinction effects, $F s<1$.

The data of the skin conductance are more difficult to interpret. During the acquisition phase the participants did show differential responding on $\mathrm{CS}+$ versus $\mathrm{CS}_{-}$, indicative of a conditioned fear response. However, no extinction of this response was observed. That is, CS + responses remained larger than CS-, and no stimulus type $\times$ trial block interaction was detected. Additionally, we did not observe any renewal effect at test. This absence was not unexpected given the lack of extinction. A possible explanation for the absence of extinction is that all participants were included in the data analyses. Some authors suggest that awareness of the CS-US or CS-noUS contingency is correlated to changes in skin conductance (see for a review Lovibond \& Shanks, 2002). However, including only the data of participants that correctly predicted the CS-(no)US relation during the acquisition and extinction phase (see criteria Section 2.4) gave similar results. A second explanation is that, due to the nature of the pictures used, the CS-US association was (partially) resistant to extinction. In a series of experiments, Öhman, Fredrikson, Hugdahl, and Rimmö (1976) demonstrated that CS-US belongingness resulted in a fast acquisition of a conditioned SCR, but slowed down subsequent extinction. Although we did not use potentially phobic stimuli in our experiment, the picture of the car and the dead child could be easily associated, especially after reading the car accident scene before onset of the acquisition. This 'belongingness' of the car, accident, and dead child might have slowed down the extinction of the SCR after the acquisition. Additionally, knowing that the US is no longer followed does not necessarily result in an immediate decline of SCR (Biferno \& Dawson, 1977), as the CS can still evoke an arousal response.

The present study is the first that compares the effects of IR plus extinction versus extinction alone using an ABA renewal paradigm. We are well aware that this first study has a number of limitations. First of all, the effects of IR were only observed in the US expectancy ratings and not in the SCR. This seems counterintuitive as the IR manipulation should affect the mental representation of the US, resulting in diminished SCR on CS presentation, but should not necessarily decrease the expectancy of the US after CS presentation. However, it is important to note that during the IR assignment the entire scene, including the CS, US, and the context, was imagined and rescripted. That is, the car (CS+) accident at the residential area no longer resulted in the death of the boy (US, IAPS 3051), but in an injured boy that survived the accident. Therefore, it is likely that at test CS+ presentation in the residential area evoked the rescripted scene and no US was expected. Although this was not explicitly our intention, this does more strongly resemble the way IR is applied in a therapeutic session in which the patient is encouraged rescript the entire traumatic scene.

This IR account seems to contradict the explanation of the slower extinction rate in the 'good' imagers group. However, during the extinction phase the ABAir group is instructed to retrieve and rescript the US memory after each CS+ presentation. This devaluation of the ending of the scene gradually progresses as the extinction phase continues and generalizes more easily to other contexts. Although the reliving of the CS-US combination might result in a slower extinction rate, this additional effort pays off as renewal is reduced.

The second limitation of this study is its generalizability to a clinical setting. In the current study only students without anxiety problems were subjected to an extinction procedure with or without IR. The evoked negative scenery cannot be compared to real traumatic experiences. Most likely it is much harder to devaluate a real experienced trauma than an instructed aversive event. 
Additionally, in a therapeutic session exposure (with or without IR) will be continued until the CR is (almost) disappeared and not after a fixed number of trials. In a future experiment it would be recommended to continue extinction until the US expectancy is near to zero and differential responses on $\mathrm{CS}+$ and $\mathrm{CS}-$ have disappeared. This enables a better insight in the influence of IR on the course of extinction and, at the same time, equalizes the onset at the renewal test for all participants. Additionally, it would be highly interesting to include a more clinically related US such as traumatic film fragments of real-life road traffic accidents (Hagenaars, Brewin, Van Minnen, Holmes, \& Hoogduin, 2010). These aversive fragments are known to evoke intrusions, which are also observed in posttraumatic stress disorder, and are vulnerable to IR procedures (Hagenaars et al., 2010).

A third point that deserves attention is the time frame in which the study is conducted. The acquisition, extinction with or without rescripting, and testing phase were all consecutively conducted without any break. This not only adds to the limited generalizability of the present study to a clinical setting, but can also disrupt memory consolidation and reconsolidation. Several studies indicated that memory stabilizes or consolidates after a couple of hours or after sleep (see for a review, Nader, 2003). Subsequent reactivation of the memory, for example during extinction learning, can alter the memory presentation, and this altered memory version can be (re)consolidated again (Quirk \& Mueller, 2007; Tronson \& Taylor, 2007). In the present study we did not separate the several phases of the experiment in time, which might have interfered with the fear memory consolidation (acquisition) and reconsolidation (extinction). Some animal studies suggest that a short interval between acquisition and extinction can interfere with the consolidation of the fear memory and favour extinction learning (Myers, Ressler, \& Davis, 2006), whereas other studies do not confirm this notion (e.g., Alvarez, Johnson, \& Grillon, 2007; Huff, Hernandez, Blanding, \& LaBar, 2009). In the present study it is not very likely that fear conditioning could not be established due to the short time interval between the acquisition and extinction phase. In all the ABA groups, at least some renewal was observed, indicating that the CS-US association was established and retrieved from memory. Although, the intention of the present study was not to unravel the influence of timing on fear acquisition, extinction, and renewal, in a future experiment it would be recommended to separate the several phases in time (e.g., 24 h delay) to ensure memory (re)consolidation.

In future experiments we will adjust several characteristics of the stimuli used, the dependent measures taken, time between the phases, and the groups included. For example, we will include CSs and contexts that are not directly related to the US and the IR assignment. This allows counterbalancing of the stimuli and a more separate US devaluation. Additionally, we would recommend checking whether the emotions evoked and arousal elicited by the control and experimental scripts are equal, as these factors might affect learning. Next to the included dependent variables we will also measure fear-potentiated startle responses, as this is a more sensitive and implicit measure to detect a conditioned fear response (Weike, Schupp, \& Hamm, 2007), and add a second VAS scale to measure arousal (or fear) next to US expectancy. This second scale would allow separating the expectancy of the US on CS presentations, which should not be affected by US-only rescripting, from the amount of arousal (or fear) elicited by the CS, which should be affected due to US-only rescripting (i.e. devalued US $\rightarrow$ diminished fear/arousal response). Another suggestion would be to increase the number of participants in order to increase power as running the ANOVA on the $\mathrm{CS}+$ renewal scores without Bonferroni corrections did reveal a difference between the ABAcont and ABAir group (LSD, $p<.05$ ), with the latter displaying less renewal. Finally, it would be important to include a group that receives IR but no extinction, enabling to measure the mere effect of IR on the diminishment and return of a CR.

In conclusion the present study is the first that assesses the additive effects of IR on extinction in an experimental setting. The results indicate that adding IR indeed resulted in less renewed responding after a change in context and that the US was valued less negative after IR. The results support the hypotheses that IR leads to US revaluation. IR might therefore, be an efficient and effective treatment procedure, directly changing the US representation, and applied to clinical practice, needing less generalization exercises, and protecting patients for return of fear. Future experimental and clinical research is needed to further explore the role of IR on US devaluation and its beneficial effects on relapse.

\section{References}

Alvarez, R. P., Johnson, L., \& Grillon, C. (2007). Contextual-specificity of short-delay extinction in humans: renewal of fear-potentiated startle in a virtual environment. Learning \& Memory, 14(4), 247-253.

Arntz, A. Imagery rescripting for personality disorders. Cognitive and Behavioral Practice, in press.

Arntz, A., Tiesema, M., \& Kindt, M. (2007). Treatment of PTSD: a comparison of imaginal exposure with and without imagery rescripting. Journal of Behavior Therapy and Experimental Psychiatry, 38(4), 345-370.

Arntz, A., \& Weertman, A. (1999). Treatment of childhood memories: theory and practice. Behaviour Research and Therapy, 37(8), 715-740.

Askew, C., Kessock-Philip, H., \& Field, A. P. (2008). What happens when verbal threat information and vicarious learning combine? Behavioural and Cognitive Psychotherapy, 36, 491-505.

Barlow, D. H., Allen, L. B., \& Basden, S. L. (2007). Psychological treatments for panic disorders, phobias, and generalized anxiety disorder. In P. E. Nathan, \& J. M. Gorman (Eds.), A guide to treatments that work (3rd ed.). (pp. 351-394) New York: Oxford University Press.

Biferno, M. A., \& Dawson, M. E. (1977). The onset of contingency awareness and electrodermal classical conditioning: an analysis of temporal relationships during acquisition and extinction. Psychophysiology, 14(2), 164-171.

Bishop, S. J. (2007). Neurocognitive mechanisms of anxiety: an integrative account. Trends in Cognitive Sciences, 11(7), 307-316.

Bouton, M. E. (2002). Context, ambiguity, and unlearning: sources of relapse after behavioral extinction. Biological Psychiatry, 52(10), 976-986.

Bouton, M. E. (2004). Context and behavioral processes in extinction. Learning and Memory, 11(5), 485-494.

Bradley, M. M., \& Lang, P. J. (1994). Measuring emotion: the Self-Assessment Manikin and the Semantic Differential. Journal of Behavior Therapy and Experimental Psychiatry, 25(1), 49-59.

Creamer, M., Foran, J., \& Bell, R. (1995). The Beck Anxiety Inventory in a non-clinical sample. Behaviour Research and Therapy, 33(4), 477-485.

Dadds, M. R., Bovbjerg, D. H., Redd, W. H., \& Cutmore, T. R. (1997). Imagery in human classical conditioning. Psychological Bulletin, 122(1), 89-103.

Davey, G. C. L. (1997). A conditioning model of phobias. In G. C. L. Davey (Ed.), Phobias: a handbook of theory, research and treatment (pp. 301-322). Chichester: John Wiley \& Sons.

Dawson, M. E., Schell, A. M., \& Filion, D. L. (2007). The electrodermal system. In J. T. Cacioppo, L. G. Tassinary, \& G. G. Berntson (Eds.), Handbook of psychophysiology (pp. 159-181). Cambridge: Cambridge University Press.

Dibbets, P., Havermans, R., \& Arntz, A. (2008). All we need is a cue to remember: the effect of an extinction cue on renewal. Behaviour Research and Therapy, 46(9), 1070-1077.

Dibbets, P., \& Maes, J. H. R. (2011). The effect of an extinction cue on ABA-renewal: does valence matter? Learning and Motivation, 42, 133-144.

Dwyer, D. M. (2003). Learning about cues in their absence: evidence from flavour preferences and aversions. Quarterly Journal of Experimental Psychology B, 56(1), 56-67.

Effting, M., \& Kindt, M. (2007). Contextual control of human fear associations in a renewal paradigm. Behaviour Research and Therapy, 45(9), 2002-2018.

Field, A. P. (2006). Is conditioning a useful framework for understanding the development and treatment of phobias? Clinical Psychological Review, 26(7), $857-875$.

Foa, E. B., Rothbaum, B. O., \& Furr, J. M. (2003). Augmenting exposure therapy with other CBT procedures. Psychiatric Annals, 33(1), 47-53.

Hagenaars, M. A., Brewin, C. R., Van Minnen, A., Holmes, E. A., \& Hoogduin, K. A. L. (2010). Intrusive images and intrusive thoughts as different phenomena: two experimental studies. Memory, 18(1), 76-84

Holmes, E. A., Arntz, A., \& Smucker, M. R. (2007). Imagery rescripting in cognitive behaviour therapy: images, treatment techniques and outcomes. Journal of Behavior Therapy and Experimental Psychiatry, 38(4), 297-305.

Huff, N. C., Hernandez, J. A., Blanding, N. Q., \& LaBar, K. S. (2009). Delayed extinction attenuates conditioned fear renewal and spontaneous recovery in humans. Behavioral Neuroscience, 123(4), 834-843. 
Hunt, M., \& Fenton, M. (2007). Imagery rescripting versus in vivo exposure in the treatment of snake fear. Journal of Behavior Therapy and Experimental Psychiatry, 38(4), 329-344.

Lang, P. J., Bradley, M. M., \& Cuthbert, B. N. (2008). International affective picture system (IAPS): Affective ratings of pictures and instruction manual. Florida: Center for Research in Psychophysiology.

Lovibond, P. F., \& Shanks, D. R. (2002). The role of awareness in Pavlovian conditioning: empirical evidence and theoretical implications. Journal of Experimental Psychology: Animal Behavior Processes, 28(1), 3-26.

Marks, I. M., Hodgson, R., \& Rachman, S. (1975). Treatment of chronic obsessivecompulsive neurosis by in-vivo exposure: a two-year follow-up and issues in treatment. British Journal of Psychiatry, 127, 349-364.

Merckelbach, H., De Jong, P., \& Arntz, A. (1991). Imagery ability and exposure in vivo in spider phobia. Behaviour Research and Therapy, 29(2), 203-205.

Muris, P., Bodden, D., Merckelbach, H., Ollendick, T. H., \& King, N. (2003). Fear of the beast: a prospective study on the effects of negative information on childhood fear. Behaviour Research and Therapy, 41(2), 195-208.

Myers, K. M., Ressler, K. J., \& Davis, M. (2006). Different mechanisms of fear extinction dependent on length of time since fear acquisition. Learning $\mathcal{E}$ Memory, 13(2), 216-223.

Nader, K. (2003). Neuroscience: re-recording human memories. Nature, 425(6958), $571-572$.

Nadler, R. T., Rabi, R., \& Minda, J. P. (2010). Better mood and better performance. Psychological Science, 21(12), 1770-1776.

Nelson, J. B., del Carmen Sanjuan, M., Vadillo-Ruiz, S., Pérez, J., \& León, S. P. (2010). Experimental renewal in human participants. Journal of Experimental Psychology: Animal Behavior Processes,

Öhman, A., Fredrikson, M., Hugdahl, K., \& Rimmö, P. A. (1976). The premise of equipotentiality in human classical conditioning: conditioned electrodermal responses to potentially phobic stimuli. Journal of Experimental Psychology: General, 105(4), 313-337.
Öst, L. G. (1989). One-session treatment for specific phobias. Behaviour Research and Therapy, 27(1), 1-7.

Öst, L. G. (1996). One-session group treatment of spider phobia. Behaviour Research and Therapy, 34(9), 707-715.

Öst, L. G. (1997). Rapid treatment of specific phobias. In G. C. L. Davey (Ed.), Phobias: a handbook of theory, research and treatment (pp. 227-246). Chichester England: John Wiley \& Sons.

Quirk, G. J., \& Mueller, D. (2007). Neural mechanisms of extinction learning and retrieval. Neuropsychopharmacology, 33(1), 56-72.

Sheehan, P. W. (1967). A shortened form of Betts' questionnaire upon mental imagery. Journal of Clinical Psychology, 23(3), 386-389.

Thomas, B. L., Larsen, N., \& Ayres, J. J. B. (2003). Role of context similarity in $A B A, A B C$, and $A A B$ renewal paradigms: implications for theories of renewal and for treating human phobias. Learning and Motivation, 34(4), 410-436.

Tronson, N. C. \& Taylor, J. R. (2007). Molecular mechanisms of memory reconsolidation. Nature Reviews Neuroscience, 8(4), 262-275.

Van der Ploeg, H. M. (1982). De zelf-beoordelings vragenlijst (STAI-DY). Tijdschrift voor Psychiatrie, 24, 576-588.

Vansteenwegen, D., Hermans, D., Vervliet, B., Francken, G., Beckers, T., Baeyens, F., et al. (2005). Return of fear in a human differential conditioning paradigm caused by a return to the original acquistion context. Behaviour Research and Therapy, 43(3), 323-336.

Watson, J. B., \& Rayner, R. (1920). Conditioned emotional reactions. Journal of Experimental Psychology, 3, 1-14.

Weike, A. I., Schupp, H. T., \& Hamm, A. O. (2007). Fear acquisition requires awareness in trace but not delay conditioning. Psychophysiology, 44(1) $170-180$.

Wild, J., Hackmann, A., \& Clark, D. M. (2007). When the present visits the past: updating traumatic memories in social phobia. Journal of Behavior Therapy and Experimental Psychiatry, 38(4), 386-401. 